\title{
A Novel Approach to Distribution Planning in an Unstructured Environment
}

\author{
Sandeep Chakravorty, Smarajit Ghosh
}

\begin{abstract}
Conductor layout plays a vital role in distribution planning. The factors such as cost associated with conductor layout, the capacity of substations and the distance of the load point from the substation is to be considered while determining the optimal conductor layout. Here in this paper a novel approach of distribution planning is proposed. In this paper a proposal for a method for locating an optimum site for a substation which has the minimum distance from the various load points is given further the conductor layout to connect the various load points using the AHP technique is suggested in this paper. By combining the GA and the AHP technique it is possible to optimize the locations of substation and the conductor layout.

The results of the discussed techniques will lead to a configuration of substation that will minimize substation construction cost. It will further lower long range distribution expenses as it will lead to optimum feeder path.

The application of the proposed methodology to a case study is presented.
\end{abstract}

Index Terms-Power distribution planning, AHP technique, optimization methods.

\section{INTRODUCTION}

Decision making features occurs in all the fields of the human activities such as scientific and technological and affects every sphere of the life. Engineering design, which entails sizing, dimensioning, and detailed element planning is also not exempt from its influence.

Basically we have been following traditional search technique for solving non linear equations. Normally, any engineering problem will have large number of solutions out of which some of are feasible and some are infeasible. The designer's task is to get the best solution out of the feasible solutions. The complete set of feasible solutions constitutes - feasible design space and the progress towards the optimal design involves some kind of search with in the space (combinatorial optimization). The search is of two kinds, namely deterministic and stochastic.

In the case deterministic search, algorithms such as steepest gradient methods are employed (using gradient concept), where as in stochastic search, random variables are introduced.

Whether search is deterministic or stochastic, it is possible to improve the reliability. Algorithm varies according to the transition rule used to improve the result.

Non traditional search and optimization methods have become popular in engineering optimization problems in recent past. These algorithms include:

1) Simulated annealing.

2) Ant colony optimization.

3) Random cost.

4) Evolution strategy.

5) Genetic Algorithm.

6) Cellular automata.

Genetic algorithms are good at taking larger, potentially huge, search spaces and navigating them looking for optimal combinations of things and solutions which we might not find in a life time.

Genetic algorithms are very different from the most of the traditional optimization methods. Genetic algorithms need design space to be converted into genetic space. So, genetic algorithms work with a coding of variables. The advantage of working with a coding variable space is that coding discretizes the search space even though the function may be continuous. A more striking difference between genetic algorithms and most of the traditional optimization methods is that GA uses a population of points at one time in the contrast to the single point approach by traditional optimization methods. This means that GA processes a number of designs at the same time. As we have seen earlier, to improve the search direction in the traditional optimization techniques, transition rules are used and they are deterministic in nature but GA uses randomized operators. Random operators improve the search space in an adaptive manner.

Three most important aspects of using GA are:

1) Definition of objective function.

2) Definition and implementation of genetic representation.

3) Definition and implementation of genetic operators.

Once these three have been defined, the GA should work fairly well beyond doubt. We can, by different variations, improve the performance, find multiple optima or parallelize the algorithms.

Genetic algorithm has been used in case of distribution planning. Since the expenditure of network expansion in distribution system is very large, planners have been trying their best seeking efficient methods to solve the problem of distribution planning. The problem of distribution planning involves optimum locations of substation and sizes of feeders to meet the requirement of load demands under various constrains such as substation and feeders capacity and network configuration. The available literature consists of work of only few researchers on the field of distribution planning. Most of them are based on mathematical 
programming such as transportation, transshipment algorithms [8, 9], mixed integer programming [10], dynamic programming [11] etc. Unfortunately only near optimal solutions have been obtained by these mathematical programming methods because almost every method has made some approximations on the model of distribution planning, moreover these methods are often complicated and time consuming.

In the work done by K.K.Li and T.S. Chung [3] genetic algorithm have been used to find the optimum location of substation to meet the load demands of 13 load points whose coordinates and MVA demands are given. Similar work has been carried out by Belgin Turkay and Taylan Artac [1], work has also been carried out by J.F.Gomez et.al.,[2]. In all the above cases planning of laying the feeders or distribution planning has been done either by man machine interface or heuristic algorithm. The papers further don't give any option of the second, third or further optimum location of a substation which may be needed in real life scenario because it may not be feasible to construct the substation in the location obtained due to various constraints. During such cases we should explore the possibilities of the second, third and so on optimum locations.

A complete survey for the solution of the planning problem of primary distribution circuits can be found in [15] and [16]. Initially methods were mainly based upon the generation and evaluation of possible solutions, oriented to small size problems, and requiring important efforts for the production of the alternatives to be evaluated. Among these the heuristic zone valuation and the generation of service areas methods may be mentioned. They rely completely upon the experience of the planning engineer and have the disadvantage that the best alternative may not be considered.

The planning problem of primary distribution networks has been basically stated as a classical mixed integer linear programming problem, where an objective function that includes both the investment and the operation cost of the network, is minimized subject to technical constraints related with the characteristics of the electric service [17]. This formulation includes binary variables linked to the fixed costs associated to some of the decision variables as well as linear approximations to represent the variable costs.

Stated as such the classical branch and bound techniques [17] have a natural application. Although the continuous research and improvement of these techniques keeps them as an alternative always to be considered, the linear approximations as well as the combinatorial complexity of the problem question their application to electric systems of real dimensions due to the requirements of excessive computing resources. This is the main reason for the application of alternative approaches, such as those classified as metaheuristic methods that are able to locate good solutions with reduced computational effort.

In order to reduce the computation requirements of the branch and bound optimization technique, the identification of the set of variables that affects most of the results was proposed in order to reduce the complexity of the mathematical model [16] however a linear approximation of the variable costs is required and excessive solution times are reported as the number of binary variables increases.

Heuristic search methods have been developed [17], [18], showing faster performance than the conventional optimization techniques but with some limitations in the goodness of the solutions to the problem that are obtained.

In [20] an open loop planning procedure is proposed where an expert system based upon the use of geographical information is applied to automate the selection of the primary and secondary circuit routes. GA's have also been applied to the solution of this problem, reducing the solution time and enhancing the obtained results [15],[18],[21],[22],[23]. In [22] a solution methodology based upon a GA is proposed for the design of primary distribution circuits considering multiple system expansion stages, where a special coding procedure is proposed to reduce the number of unfeasible solutions evaluated by the algorithm. These methodologies have been improved significantly. An evolutionary programming algorithm is presented in [25], considering the uncertainties of the possible scenarios. In [16] and [24] the potential of the GA is shown in comparison with classical optimization techniques to solve the planning problem. An integer variable coding scheme was used to facilitate the consideration of different conductor sizes and substation sizes also new genetic operators were proposed to improve the performance of the algorithm. In [26] the approach is expanded to consider the multiple development stages as well as multiple objectives. In [31] an evolutionary approach is applied to the design of a medium voltage network using a detailed model of the network.

Going through the literature survey, here in this paper we suggest a method where we can have the optimum location of all the substations required to meet the load points. Here the optimum location as well as the load distribution is done plainly by using the GA technique and no necessary assumption is made. While suggesting the conductor layout its sometimes necessary to have some experts rating on various factors such as the cost of materials for laying the conductor through a particular path, the cost of labor charges that may be incurred while laying the conductor etc. Conventional techniques for suggestion of conductor layout do not take into consideration such factors and decisions of experts. Here to meet the given drawback we have suggested an AHP technique for deciding the layout of the feeder path.

\section{Proposed Methodology}

Let us have a system where thirteen load points are present which are to be fed from two substations depending on the capacity and the load demands. The layout of feeders for feeding the thirteen load points depends on the following factors:

1) Substation Capacity

2) Load demands

3) Distance of the load from the substation

4) Expenditure incurred in laying the feeder

Substation location has been obtained by the use of genetic algorithm. In case its not feasible to have the substation at the optimum location obtained by the use of genetic algorithm, the second optimum location is considered which too is obtained by the use of genetic algorithm. The distribution layout is done using AHP 
technique. The pictorial representation of the problem is as shown in fig 1.

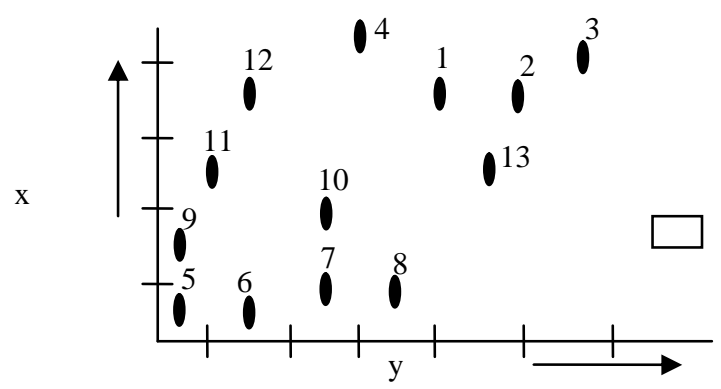

$\square$ indicates load
indicates

Fig 1 (Representation of the problem)

GA technique has been used to obtain the optimum location. A detail of the algorithm to obtain the load distribution and for obtaining the optimum location of all the substations are stated in [33].

Now for the conductor layout Analytical Hierarchy Process (AHP) technique is used. AHP is a multi-criteria decision making process that allows working with both numerical factors and those that are un-tangible and subjective. It provides a structured way to determine the weighting factors for each criterion and applies the weights to the comparison of alternatives. AHP uses pair wise comparisons of design concepts to convert a statement

( "this is vary important", "this is not so important") into a numerical value.

To determine whether node $\mathrm{Y}$ is to be connected to substation or to node $\mathrm{X}$ the following factors have been considered:

1) Distance of node $Y$ from the substation and node $X$.

2) Cost of material in laying the conductor from substation and node $\mathrm{X}$.

3) Labor charges incurred in laying the conductor from substation and node $\mathrm{X}$.

In deciding how much more strongly does this criterion influence the outcome than the other criterion a nine point scale has been used ( 1 indicates equal importance; 3 indicates moderate importance; 5 indicates strong importance; 7 indicates very strong importance; 9 indicates extreme importance)

The process is to be repeated for all other nodes that are to be connected. The number of input for each simulation keeps on increasing as for every node the number of options keeps on increasing.

\section{CASE STUdY}

For the thirteen load point problem representation shown in Fig 1 a optimum location is obtained by the use of genetic algorithm

After running the program with the given coordinates of the load points and their respective load demands the optimum location that was obtained using the GA technique was coordinates (5 3). The result in tabular form is as shown

\begin{tabular}{|c|c|c|c|c|}
\hline $\begin{array}{l}\text { Load } \\
\text { points }\end{array}$ & $\begin{array}{l}\text { X } \\
\text { coordinates }\end{array}$ & $\begin{array}{l}\text { Y } \\
\text { coordinates }\end{array}$ & $\begin{array}{l}\text { Load } \\
\text { demands } \\
\text { in MVA }\end{array}$ & $\begin{array}{l}\text { Dist. } \\
\text { From } \\
\text { Sub } \\
\text { station }\end{array}$ \\
\hline 1 & 8 & 7 & 5 & 5 \\
\hline 2 & 10 & 7 & 12 & 6.4 \\
\hline 3 & 11 & 8 & 7 & 7.8 \\
\hline 4 & 6 & 9 & 5 & 6 \\
\hline 5 & 1 & 1 & 7 & 4.4 \\
\hline 6 & 3 & 1 & 11 & 2.8 \\
\hline 7 & 5 & 2 & 8 & 1 \\
\hline 8 & 7 & 2 & 3 & 2.2 \\
\hline 9 & 1 & 3 & 4 & 4 \\
\hline 10 & 5 & 4 & 12 & 1 \\
\hline 11 & 2 & 5 & 6 & 3.6 \\
\hline 12 & 3 & 7 & 3 & 4.4 \\
\hline 13 & 9 & 5 & 4 & 4.4 \\
\hline
\end{tabular}

Let us assume the capacity of the first substation is 55 MVA and that of substation two is 30 MVA. Now to get the optimum location of the two substation we sort the result obtained in ascending order as per their distances from the location thus obtained (5 3) and in case the distance turns out to be same for two load points we give preference to the MVA rating.

\begin{tabular}{|c|c|c|c|c|}
\hline $\begin{array}{l}\text { Load } \\
\text { points }\end{array}$ & $\begin{array}{l}\mathbf{X} \\
\text { coordinates }\end{array}$ & $\begin{array}{l}\text { Y } \\
\text { coordinates }\end{array}$ & $\begin{array}{l}\text { Load } \\
\text { demands } \\
\text { in MVA }\end{array}$ & $\begin{array}{l}\text { Dist. } \\
\text { From } \\
\text { Sub } \\
\text { station }\end{array}$ \\
\hline 7 & 5 & 2 & 8 & 1 \\
\hline 10 & 5 & 4 & 12 & 1 \\
\hline 8 & 7 & 2 & 3 & 2.2 \\
\hline 6 & 3 & 1 & 11 & 2.8 \\
\hline 11 & 2 & 5 & 6 & 3.6 \\
\hline 9 & 1 & 3 & 4 & 4 \\
\hline 12 & 3 & 7 & 3 & 4.4 \\
\hline 13 & 9 & 5 & 4 & 4.4 \\
\hline 5 & 1 & 1 & 7 & 4.4 \\
\hline 1 & 8 & 7 & 5 & 5 \\
\hline 4 & 6 & 9 & 5 & 6 \\
\hline 2 & 10 & 7 & 12 & 6.4 \\
\hline 3 & 11 & 8 & 7 & 7.8 \\
\hline \multicolumn{5}{|c|}{ Table 3 (The result sorted in ascending form) } \\
\hline
\end{tabular}

As per the sorted list now we allot load points (7 1086 $\left.\begin{array}{llll}11 & 9 & 12 & 5\end{array}\right)$ to substation 1 and load points ( $\left(\begin{array}{lllll}13 & 1 & 4 & 2 & 3\end{array}\right)$ to substation 2. Now with the allotted load points we again run the genetic algorithm to get the optimum location of substation one and two. The fitness function remains the same for choosing the location for the two substation i.e. product of load demand and distance from the substation.

Applying GA we get the location for substation 1 as (3 2) and that of substation 2 as (9 7). In case the optimum location cannot be met due to some constrains we can get the second or third optimum location and so on. Now for determining the conductor layout we apply the AHP technique. Load point 1 being close to substation 2 we connect load point 1 to substation 2 . Now to decide whether load point 2 needs to get connected to substation 2 or to load 
point 1 we apply AHP as shown below:

\section{Applying AHP:}

Determining weighing factors:

\begin{tabular}{|l|l|l|l|}
\hline & Distance & Labor cost & $\begin{array}{l}\text { Material } \\
\text { cost }\end{array}$ \\
\hline Distance & 1 & 7 & 9 \\
\hline Labor cost & $1 / 7$ & 1 & 7 \\
\hline Material cost & $1 / 9$ & $1 / 7$ & 1 \\
\hline
\end{tabular}

Normalization matrix for criteria:

\begin{tabular}{|l|l|l|l|}
\hline & Distance & Labor cost & $\begin{array}{l}\text { Material } \\
\text { cost }\end{array}$ \\
\hline Distance & $63 / 79$ & $49 / 57$ & $9 / 17$ \\
\hline Labor cost & $9 / 79$ & $7 / 57$ & $7 / 17$ \\
\hline Material cost & $7 / 79$ & $1 / 57$ & $1 / 17$ \\
\hline
\end{tabular}

\section{Priority vector for criteria:}

Distance $=(63 / 79+49 / 57+9 / 17) / 3=0.729$

Labor cost $=(9 / 79+7 / 57+7 / 17) / 3=0.216$

Material cost $=(7 / 79+1 / 57+1 / 17)=0.055$

Determining weighing factors taking into consideration distance:

\begin{tabular}{|l|l|l|}
\hline & Substation 2 & Load point 1 \\
\hline Substation 2 & 1 & 5 \\
\hline Load point 1 & $1 / 5$ & 1 \\
\hline
\end{tabular}

Normalization matrix:

\begin{tabular}{|l|l|l|}
\hline & Substation 2 & Load point 1 \\
\hline Substation 2 & $5 / 6$ & $5 / 6$ \\
\hline Load point 1 & $1 / 6$ & $1 / 6$ \\
\hline
\end{tabular}

\section{Priority vector:}

Substation $2=(5 / 6+5 / 6) / 2=5 / 6$

Load point $1=(1 / 6+1 / 6) / 2=1 / 6$

Determining weighing factors taking into consideration labor cost:

\begin{tabular}{|l|l|l|}
\hline & Substation 2 & Load point 1 \\
\hline Substation 2 & 1 & 5 \\
\hline Load point 1 & $1 / 5$ & 1 \\
\hline & & \\
& & \\
\hline
\end{tabular}

Normalization matrix:

\begin{tabular}{|l|l|l|}
\hline & Substation 2 & Load point 1 \\
\hline Substation 2 & $5 / 6$ & $5 / 6$ \\
\hline Load point 1 & $1 / 6$ & $1 / 6$ \\
\hline
\end{tabular}

Priority vector:

Substation $2=(5 / 6+5 / 6) / 2=5 / 6$

Load point $1=(1 / 6+1 / 6) / 2=1 / 6$

Determining weighing factors taking into consideration material cost:

\begin{tabular}{|l|l|l|}
\hline & Substation 2 & Load point 1 \\
\hline Substation 2 & 1 & 9 \\
\hline Load point 1 & $1 / 9$ & 1 \\
\hline
\end{tabular}

Normalization matrix:

\begin{tabular}{|l|l|l|}
\hline & Substation 2 & Load point 1 \\
\hline Substation 2 & $9 / 10$ & $9 / 10$ \\
\hline Load point 1 & $1 / 10$ & $1 / 10$ \\
\hline
\end{tabular}

Priority vector:

Substation $2=(9 / 10+9 / 10) / 2=9 / 10$

Load point $1=(1 / 10+1 / 10) / 2=1 / 10$

Finally we complete the AHP matrix:

Substation $2=(5 / 6) \times 0.729+(5 / 6) \times 0.216+(9 / 10) \times 0.055$

$$
=0.8366
$$

Load point $1=(1 / 6) \times 0.729+(1 / 6) \times 0.216+(1 / 10) \times 0.055$ $=0.1623$

So we connect the load point 2 to substation 2 .

Proceeding in the similar manner to determine whether load point 3 is to be connected to substation 2 , or load point 1 , or load point 2 .

Determining weighing factors taking into consideration distance:

\begin{tabular}{|l|l|l|l|}
\hline & Substation 2 & Load point 1 & $\begin{array}{l}\text { Load } \\
\text { point 2 }\end{array}$ \\
\hline Substation 2 & 1 & 5 & $1 / 5$ \\
\hline Load point 1 & $1 / 5$ & 1 & $1 / 9$ \\
\hline Load point 2 & 5 & 9 & 1 \\
\hline
\end{tabular}

Normalization matrix:

\begin{tabular}{|l|l|l|l|}
\hline & Substation 2 & Load point 1 & $\begin{array}{l}\text { Load } \\
\text { point 2 }\end{array}$ \\
\hline Substation 2 & $5 / 31$ & $1 / 3$ & $9 / 59$ \\
\hline Load point 1 & $1 / 31$ & $1 / 15$ & $5 / 59$ \\
\hline Load point 2 & $25 / 31$ & $3 / 5$ & $45 / 59$ \\
\hline
\end{tabular}

Priority vector:

Substation $2=(5 / 31+1 / 3+9 / 59) / 3=0.2157$

Load point $1=(1 / 31+1 / 15+5 / 59) / 3=0.0612$

Load point $2=(25 / 31+3 / 5+45 / 59) / 3=0.723$

Determining weighing factors taking into consideration labor cost:

\begin{tabular}{|l|l|l|l|}
\hline & Substation 2 & Load point 1 & $\begin{array}{l}\text { Load } \\
\text { point 2 }\end{array}$ \\
\hline Substation 2 & 1 & 3 & $1 / 3$ \\
\hline Load point 1 & $1 / 3$ & 1 & $1 / 5$ \\
\hline Load point 2 & 3 & 5 & 1 \\
\hline
\end{tabular}

Normalization matrix:

\begin{tabular}{|l|l|l|l|}
\hline & $\begin{array}{l}\text { Substation } \\
2\end{array}$ & Load point 1 & $\begin{array}{l}\text { Load } \\
\text { point 2 }\end{array}$ \\
\hline Substation 2 & $3 / 13$ & $1 / 3$ & $5 / 23$ \\
\hline Load point 1 & $1 / 13$ & $1 / 9$ & $3 / 23$ \\
\hline Load point 2 & $9 / 13$ & $5 / 9$ & $15 / 23$ \\
\hline
\end{tabular}

\section{Priority vector:}

Substation $2=(3 / 13+1 / 3+5 / 23) / 3=0.2604$

Load point $1=(1 / 13+1 / 9+3 / 23) / 3=0.1061$

Load point $2=(9 / 13+5 / 9+15 / 23) / 3=0.6333$

Determining weighing factors taking into consideration material cost:

\begin{tabular}{|l|l|l|l|}
\hline & Substation 2 & Load point 1 & Load point 2 \\
\hline Substation 2 & 1 & 5 & $1 / 5$ \\
\hline
\end{tabular}




\begin{tabular}{|l|l|l|l|}
\hline Load point 1 & $1 / 5$ & 1 & $1 / 9$ \\
\hline Load point 2 & 5 & 9 & 1 \\
\hline
\end{tabular}

\section{Normalization matrix:}

\begin{tabular}{|l|l|l|l|}
\hline & Substation 2 & Load point 1 & Load point 2 \\
\hline Substation 2 & $5 / 31$ & $1 / 3$ & $9 / 59$ \\
\hline Load point 1 & $1 / 31$ & $1 / 15$ & $5 / 59$ \\
\hline Load point 2 & $25 / 31$ & $3 / 5$ & $45 / 59$ \\
\hline
\end{tabular}

\section{Priority vector:}

Substation $2=(5 / 31+1 / 3+9 / 59) / 3=0.2157$

Load point $1=(1 / 31+1 / 15+5 / 59) / 3=0.0612$

Load point $2=(25 / 31+3 / 5+45 / 59) / 3=0.723$

Finally we complete the AHP matrix:

Substation $2=0.2157 \times 0.729+0.2604 \times 0.216+0.2157 \times$ $0.055=0.2253$

Load point $1=0.0612 \times 0.729+0.1061 \times 0.216+0.0612 \times$ $0.055=0.0708$

Load point $2=0.723 \times 0.729+0.6333 \times 0.216+0.723 \times$ $0.055=0.7036$

So we connect the load point 3 to load point 2 .

Proceeding in the manner stated above we get the conductor layout as shown in fig 2.

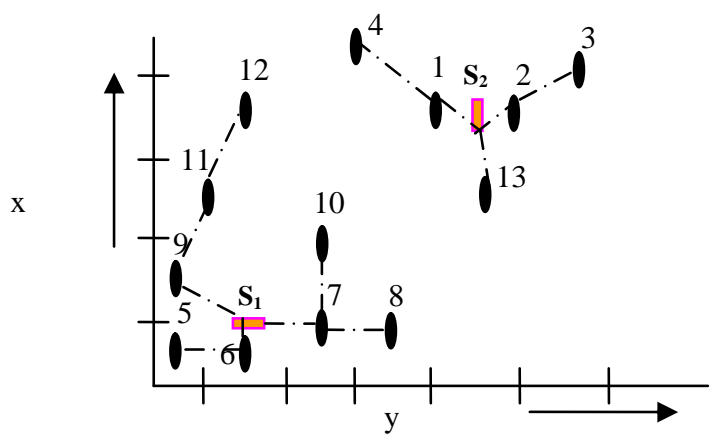

Fig 2 (Showing the final conductor layout from the substations)

\section{CONCLUSION}

Experts rating on various factors such as

1) The distance between two load points.

2) The cost of materials for laying the conductor through a particular path.

3) The cost of labor charges that may be incurred while laying the conductor etc.

are to be considered before deciding the conductor layout in distribution planning system. Conventional techniques for suggestion of conductor layout do not take into consideration such factors and decisions of experts. Here to meet the given drawback we have suggested an AHP technique for deciding the layout of the feeder path.

The method gives an optimum conductor layout considering the stated factors.

\section{DISCUSSION}

Here in the suggested method of AHP factors keeps on increasing as we go from one node to another as for every node the options keeps on increasing. We can further think of taking into account such factors and experts decision while deciding the optimum location of the substations.

\section{REFERENCES}

[1] Belgin Turkay and Taylan Artac. (2005), "Optimal Distribution Network Design Using Genetic Algorithm," Electric Power Components and Systems, 33; 513-524.

[2] J.F.Gomez et al. (2004), "Ant Colony System Algorithm for the Planning of Primary Distribution Circuits," IEEE Transactions on Power Systems, Vol. 19, No. 2.

[3] K.K.Li and T.S.Chung. (2004), "Distribution Planning Using Rule Based Expert System Approach," IEEE International Conference on Electric Utility Deregulation and Power Technologies(DRPT 2004).

[4] Eloy Diaz-Dorado et al. (2002), "Application of Evolutionary Algorithms for the Planning of Urban Distribution Networks of Medium Voltage," IEEE Transaction Power System, Vol. 17, No. 3.

[5] Sujit Mondal and Anil Pahwa. (2002), "Optimal Selection of Conductors for Distribution Feeders," IEEE Transactions on Power Systems, Vol. 17, No. 1.

[6] D.L.Wall et al. (1979), "An Optimization Model for Planning Radial Distribution Networks," IEEE Transactions on Power Apparatus and Systems, Vol..PAS-98, No. 3.

[7] W.M. Lin et al. (1997), "A new Approach for Distribution Feeder Reconfiguration for Loss Reduction and Service Restoration," IEEE PES.

[8] Dale M.Crawford and Stewart B. Holt. (1975), "A Mathematical Optimization Technique For Locating Sizing Distribution Substations, and Driving Their Optimal Service Areas," IEEE. Trans. on Power Apparatus and Systems, Vol. PAS 94, No. 2, pp. 230-235.

[9] M.A. El-Kady. (1984), "Computer Aided planning of Distribution Substation and Primary Feeders," IEEE. Trans. on Power Apparatus and Systems, Vol. PAS 103, No. 6, pp. 1183-1189. [10] T.Gonen, I.J. Ramirez-Rosado. (1987), "Optimal Multi Stage Planning of Power Distribution Systems," IEEE Trans. on Power Delivery, Vol. PWRD-2, No.2, pp 512-519.

[10] J.Partanen. (1990), "A Modified Dynamic Programming Algorithm for Sizing, Locating and Timing of Feeder Reinforcements," IEEE Trans. on Power Delivery, Vol.5, No.1, pp 227-283.

[11] V.Mirinda, J.V.Ranito, L.M. Proenca. (1994), "Genetic Algorithm in Optimal Multistage Distribution Network Planning", IEEE Trans. on Power Systems, vol. 9, No. 4, pp. 1927-1933.

[12] S.Chakravorty and M.Thukral. (2007), "Optimal Allocation of Load Using Optimization Technique", International conference CISSE

[13] Robert H.Fletcher. (2007), "Optimal Distribution System Horizon Planning: Application," IEEE Trans. Power Syst., Vol. 22.

[14] S.K.Khator and L.C. Leung. (1997), "Power Distribution Planning: A review of models and issues," IEEE Trans. Power Syst., vol.12, pp 1151-1159.

[15] J.L.Bernal-Agustin.(1998), " Aplicacion de Algoritmos Geneticos al Diseno Optimo de Sistemas de Distribucion de Energia Electrica," Ph.D. dieesrtation, University de Zaragoza, Espana.

[16] J.T.Boardman and C.C. Meekiff. (1985), " A branch and bound formulation of an electricity distribution planning problem," IEEE Trans. Power App. Syst., vol. 104, pp. 2112-2118.

[17] K.Nara et al. (1992), "Distribution system expansion planning b multi- $\quad$ stage branch exchange," IEEE Trans. Power syst., vol. 7, pp.208-214.

[18] B.Turkay and T.Artac. (2005), "Optimal distribution network design using genetic algorithm," Taylor \& Francis Electric Power Components and Systems, 33. pp. 513-524.

[19] Z. Sumic et al. (1993), "Automated underground residential distribution Part 2: Prototype implementation and results," IEEE Trans. Power Delivery, vol. 8, pp. 644-650.

[20] E.C. Yeh, S.S. Venkata, and Z. Sumic. (1996), "Improved distribution system planning using computational evolution," IEEE Trans. Power Syst., vol. 11, pp. 668-674.

[21] V.Miranda, J.V.Raito, and L.M.Proenca. (1994), "Genetic algorithm in optimal multistage distribution network planning," IEEE Trans. Power Syst., vol.9, pp.1927-1933.

[22] I.J.Ramirez-Rosado and J.L.Bernal Agustin. (1995), "Optimization of power distribution network design by application of genetic algorithm," Int.J.Power Energy Syst., vol.15, no.3, pp.104-110.

[23] Ramirez Rosado, I.J., Bernal Agustin, J.L. (1998), "Genetic algorithm applied to design of large power distribution system," IEEE Trans. Power Syst., vol.13, pp.696-703.

[24] P.M.S.Carvalho and L.A.F.M. Ferreira. (1998), "Optimal distribution network expansion planning under uncertainty by evolutionary decision convergence," Int.J.Elect. Power Energy Syst., vol. 20, no. 2, pp. 125-129.

[25] M.Dorigo, V.Maniezzo and A.Coloni. (1996), "The ant system: Optimization by a colony of cooperating agents," IEEE Trans. Syst., Man, Cybern.B, vol. 26, pp. 29-41. 
[26] M.Dorigo amd L.M.Gambardella. (1997), "Ant colony system: A cooperative learning approach to the traveling salesman problem," IEEE Trans. Evol.. Comput., vol. 1, pp. 29-41.

[27] Y.Da Silva, J.Di Girolano and A.Ferreira. (1999), "Optimizacion de circuitos aereos de distribucion en campos petroleros" (in Spanish), in Proc. IEEE Andean Region Conf., vol. II, 1, pp. 967-972.

[28] C.E.Advirson. (1940), "Diversified demand method of estimation residential distribution transformer load." Edison Elect. Inst. Bulletin, vol. 8, pp. 469-479.

[29] A.J.Urdaneta and V.Chankong. (1989), "A multiple objective minimax approach for controller

[30] setting of systems running under disturbances," in Control: Theoryand Advanced Technology, Invited Paper Special Issue on Multiple Objective, Discrete, Dynamic Systems. Tokyo, Japan: MITA,vol.5.

[31] E.Diaz Dorado, J.Cidras and E. Miguez. (2002), "Application of evolutionary algorithms for the planning of urban distribution networks of medium voltage," IEEE Trans. Power Syst., vol. 17, pp. 879-884.

[32] Sandeep Chakravorty and Manish thukral. (2009), "Choosing Distribution Sub Station Location Using Soft Computing Technique", International Conference on Advances in Computing, Communication and Control - 2009 Mumbai. India.

[33] Sandeep Chakravorty, Smarajit Ghosh, (2009), "An Improvised Method for Distribution of Loads and Configuration of Distribution Sub Station", International Journal of Engineering Research and Industrial Applications. Vol.2 No. II, pp. 269-280. 2009.

[34] Sandeep Chakravorty, Smarajit Ghosh, "Fuzzy Based Distribution Planning Technique", Journal of Electrical Engineering.Politehnica Publishing House.

[35] Sandeep Chakravorty and Manish Thukral. (2008), "Using Genetic Algorithm to Determine the Optimum Location of the Sub Station", International Workshop and IEEE EDS Mini Colloquia on NAnometer CMOS Technology (WIMNACT 2008) on Nanoelectronics 6-8 March 2008.

[36] Sandeep Chakravorty, Smarajit Ghosh, (2009), "Distribution Planning Based on Reliability and Contingency Criteria", International Journal of Computer and Electrical Engineering. Vol.1 No. 2, pp. 156-161. June 2009.

Sandeep chakravorty serving as a Reader in Sikkim Manipal Institute of Technology, Department of Electrical and Electronics Engineering under Sikkim Manipal University. He did his B.E. from Sikkim Manipal Institute of Technology, Sikkim in Electrical \& Electronics Engineering and M.E. in Software Engineering from Birla Institute of Technology, Mesra, Ranchi. India. Currently he is doing his Ph.D. in Sikkim Manipal University.

Smarajit Ghosh serving as a Professor in Thapar University, Department of Electrical and Instrumentation Engineering. He did his B.Tech., M.Tech. in Electrical Machines and Power Systems from Calcutta University in 1994 and 1996 respectively. Finally, he did his Ph.D. from Indian Institute of Technology, Khapargpur, India in 2000. His research areas include load-flow study, network reconfigurations, optimum capacitor allocation, application of soft computing in Elctrical Power Distribution Systems. 